\title{
Damage and Strength for Notched Plates of Short Glass Fiber Reinforced Polypropylene
}

\author{
Toshihiro Yamamoto, Recycling and Eco-Tech., Fukuoka Univ., Fukuoka, Japan \\ Hiizu Hyakutake, Dept. of Mechanical Engineering. Fukuoka Univ., Fukuoka, Japan \\ Hidetoshi Takeda, Plastics Technical Center. Idemitsu Petrochemical Co., Ltd., Ichihara, Japan
}

Studying stress distribution near the notch root, we have obtained a failure criterion for notched bars under static load. The criterion is based on the concept of the severity near the notch root. The severity is determined by both the maximum elastic stress at the notch and the notch-root radius. According to this failure condition, the maximum elastic stress at fracture, omax, $\mathrm{c}$ is determined by the notch-root radius ponly in the material. The validity of the concept of the severity near the notch root has been confirmed for notched plates of several engineering plastics and FRP under static load tests.

For notched FRP plates under tension, the damaged zone initiates and grows near the notch root prior to catastrophic fracture. We observed the decrease of luminance near the notch root according to the initiation and growth of damaged zone. The decrease of luminance in the damaged zone is associated with irreversible microfracture near the notch root. To evaluate quantitatively the damage near the notch root, we measured the luminance distributions by means of the luminance measurement technique with a CCD camera. We have shown that the process of the damage initiation and growth under static load can be explained on the concept of the severity near the notch root.

The aims of the present study are to confirm experimentally the validity of the failure criterion based on the concept of severity near the notch root for the initiation and growth of the damage and fracture strength of notched FRP plates. An experimental method is presented which examines the strength and damage of notched plates of glass fiber-reinforced polypropylene (GF/PP) subjected to static tension. We used GF/PP plates of 3 $\mathrm{mm}$ thick that were made by injection molding. The plate contains $30 \%$ E-glass fiber by weight. The mean value of fiber length had the following two levels: $1.2 \mathrm{~mm}$ and $0.4 \mathrm{~mm}$. The diameter of the fiber is about $0.01 \mathrm{~mm}$. Notched specimens having a constant width were notched in a U-shape on both sides at the midpoint of their length. The notch-root radius $\rho$ were $0.5,1$ and $2 \mathrm{~mm}$. In addition, the notch depth ranged from 1 to $4 \mathrm{~mm}$. Tension tests were performed by an Instron-type testing machine at a constant cross-head speed at room temperature.

The experiment shows that the fracture strength of notched GF/PP specimen was determined only by the notch-root radius for the materials of a constant fiber length. The initiation and the growth of the damaged zone near the notch root are determined by both the maximum elastic stress at the notch root and notch-root radius for the materials of a constant fiber length. On the basis of the idea of severity near the notch root mentioned above, the experimental results of all notched specimens can be explained. The fracture strength and the process of initiation and growth of the damaged zone were dependent on the fiber length. 